\title{
A dupla formação dos contratos de consumo
}

\begin{abstract}
André R. C. Fontes ${ }^{1}$
\section{Resumo}

O artigo trata de evolução do direito do consumidor em um confronto com o direito civil.

Palavras-chave: Pandectismo; Negócio; Declaração.
\end{abstract}

\begin{abstract}
The article deals with the evolution ofconsumer law in confrontation with civil law.

Keywords: Pandectism; Business, Declaration.

É do Século XIX a Teoria do Negócio Jurídico; e se integrará nesse mesmo século ao Direito Civil pelas mãos dos seus fautores - os integrantes de um movimento na Alemanha chamado Pandectismo. Preocupados que estavam em usar o Direto Romano como um direito comum a todos os alemães dispersos em vários Estados - antes da unificação de 1870 -, e após, como fonte material do conhecimento jurídico e na elaboração de seu Código Civil e de todo o sistema jurídico que dele adviria, forjaram os alemães um número de conceitos e ideias que se tornou um marco sem paralelo na História do Direito. E é por essa contribuição que a família jurídica, na qual integra o Brasil, passou a se chamar de Romano-Germânica.
\end{abstract}

E há uma questão de grande importância no confronto da origem do negócio jurídico com as raízes do contrato. E exprimiremos melhor a ideia com uma afirmação direta e objetiva:

\footnotetext{
${ }^{1}$ Doutor em Direito pela Universidade do Estado do Rio de Janeiro - UERJ (2005), Doutor em Filosofia pela Universidade Federal do Rio de Janeiro - UFRJ (2007), Doutor em Ciências em História das Ciências, das Técnicas e Epistemologia pela Universidade Federal do Rio de Janeiro - UFRJ (2007), Doutor em Ciências Ambientais e Florestais pela Universidade Federal Rural do Rio de Janeiro - UFRRJ (2015), Mestre em Direito pela Universidade do Estado do Rio de Janeiro - UERJ (2002) e Mestre em Direito Constitucional pela Universidade Federal Fluminense - UFF (2013). Professor Associado da Universidade Federal do Estado do Rio de Janeiro - UNI-RIO. Professor no Programa de Pós-Graduação em Direito da Universidade Federal do Estado do Rio de Janeiro - UNI-RIO. Desembargador do Tribunal Regional Federal da $2^{\text {a }}$ Região (Rio de Janeiro e Espírito Santo).
} 
que na presente época vigora um entendimento majoritário segundo o qual o negócio jurídico foi elaborado por alemães, a partir dos textos romanos antigos, e que a isso se soma a complementação de que os juristas romanos somente teriam elaborado o que poderíamos denominar de uma Teoria dos Contratos. Ao descreverem a formação do negócio jurídico, convergem assim os autores alemães, em sua maioria, de que é uma criação moderna, e especificamente da Pandectística alemã, no Século XIX.

Se divergências surgiram acerca da origem alemã do negócio jurídico, estavam fundadas em um único argumento: os autores modernos geralmente se utilizam do estudo dos textos de Direito Romano porque foram os juristas romanos que tiveram a intuição do que hoje se entende e se consagra. E ainda para se desvendar o desconhecido em Direito ou afastar divergências ou controvérsias jurídicas, devem ser elas remetidas ao Direito Romano. Então, insistiremos na premissa de que os romanos se dedicaram à formulação das bases dos contratos, mas não dos atos jurídicos, a despeito de os autores reconhecerem uma unidade progressiva e compartimentada que vem do Direito Romano até os nossos tempos na formação dos negócios e de seus desdobramentos no Direito Privado. Importa sublimar que as duas orientações reconhecem que a expressão negócio jurídico foi usada no século anterior, em 1784, pelo alemão Adolph Dietrich Weber (especificamente no ano de 1784).

A doutrina do negócio jurídico é total e harmônica. Total porque abrange toda declaração de vontade do agente dirigida a um fim. Harmônica porque se compatibilizou com o sistema do Direito, e mais especialmente do Direito Privado, mediante o recurso da Teoria (kantiana) da autonomia da vontade. Reproduzimos a ideia de Kant de maneira categórica: autonomia da vontade é liberdade como poder. É com a Filosofia de Kant que os estudiosos disseram que o negócio jurídico era um ato de liberdade. E ainda, que o negócio jurídico é instrumento de um poder - o poder de liberdade kantiana denominado autonomia da vontade. Contudo, esse poder em Direito assumirá contornos mais técnicos e específicos e também um nome novo: a autonomia privada.

A unidade interna, a inteireza, a lógica irrefutável e a etapa superior do desenvolvimento do negócio jurídico - reconhecida até pelos seus contraditores - são o resultado da aplicação em todas as suas partes integrantes de uma concepção teórica e de um método únicos, ou seja, concentrados na ideia de liberdade. É impossível compreender profundamente o negócio jurídico sem assimilar a sua base de liberdade seja como resultado de um poder de liberdade (autonomia privada) seja como um ato de liberdade (declaração livre de vontade).

As fontes imediatas do Direito Civil brasileiro são o Código Civil e as lei esparsas. A unidade e a interconexão de todas as normas de Direito Privado não excluem a existência de peculiaridades e inclui certa independência, tanto de algumas normas desse Direito como de grupo de ramos diversos do Direito, contidas em atos isolados que são integrados ao que conhecemos por Direito privado. Surge por isso a necessidade de se examinar especialmente quais são os elementos componentes e as fontes do Sistema de Direito Privado brasileiro. 
É complexa formação do que hoje entendemos por contrato se tomarmos como ponto de partida os momentos iniciais do Direito Romano. Inicialmente, era o contrato visto como uma mera operação prática e que sofreu lenta progressiva alteração em seu regime até ser reconhecer a existência de uma vontade para um acordo no qual se baseava. No curso da evolução, somente quatro figuras (compra e venda, a locação, o mandato e a sociedade) inicialmente seriam assim consideradas (como contrato) - o que permite pôr a descoberto que, fora desse grupo, entendia-se que haveria um contrato, mas mero pacto - portanto, sem a possibilidade de ter efeitos jurídicos, dos quais se destaca o de e ser exigido e cumprido. Uma peculiaridade da evolução deve ser lembrada: a de que compreensão que se tem da vontade nos contratos brota no período Direito Medieval, por influência da Igreja Católica e em especial dos canonistas, que eram mais voluntaristas, ou seja, adeptos de um poder da vontade. Nos períodos seguintes o contrato recebe uma outra influência, da Escola de Direito Natural, que expande seu espectro para campos que vão além da concepção de gerador de obrigações - nos quais o Brasil não seguirá -, para incluir a possibilidade do contrato transferir, por si, a propriedade ou ainda para efeitos não obrigacionais, como ocorre com o casamento. Por conseguinte, tornou-se o contrato uma das figuras continuadas de maior caracterização do Direito, e de ampla e progressiva constância desde os primórdios do Direito até os nossos tempos.

$\mathrm{Na}$ formação econômica e social da civilização moderna, pode-se constatar no desenvolvimento do contrato nos compromissos que serviram de forças motrizes do alargamento da produção econômica e de toda força produtiva conhecida. O contrato sintetiza a forma do homo economicus aplacar suas necessidades. É o contrato o ponto para o qual converge toda rede de elementos que proporcionam a subsistência de todo o grupamento humano. O contrato se revela como solução para as fases de evolução do ser humano, em um verdadeiro desenrolar em forma de espiral da qual faz depender a hereditariedade existente entre o velho e o novo a tal ponto que condicionaria a uma regressão da atividade do homem aos seus momentos primários.

Nós observamos que o mundo circundante manifesta-se por uma série de aspectos, e quanto a isso, relativamente ao contrato, além sua função econômica, aponta-se uma outra, de cariz civilizador: a educativa. O ser social é primário na busca de soluções conjuntas e buscar aproximar-se e a vencer desafios e barreiras. É com o contrato que os próprios homens constroem a vida social e harmonizam interesses, por meio de uma necessidade vital de conjugar o esforço alheio ao seu. Os povos abrem caminhos para a ascensão da atividade de construção de um grande sistema prevenção e respeitabilidade para convergir nas forças do progresso. A superação de contradições e antagonismos segue em linha reta para a harmonia e satisfação de todos independente da natureza dos laços que os unem.

O contratante tem a consciência do seu direito como contraparte e do direito como concepção abstrata que viria a tutelar seus interesses. Naturalmente, anui orientar-se em de tal forma que realiza dentro das suas relações privadas um pouco da ordem jurídica em vigor. Certo é que, por ser fonte criadora de direitos, no geral contrato pode ser usado na linguagem 
quotidiana de uma forma bem especial, como algo que se assemelha à lei, embora no âmbito mais restrito, já que sabidamente a lei brasileira não usa a expressão napoleônica de que o contrato faz lei entre as partes. Serve assim de fundamento para um tipo difuso e capilarizado de poder jurígeno. Tanto na linguagem da lei como na linguagem comum, o uso do termo contrato designa resultados desejados em conjunto com a percepção geral que o torna perfeitamente admissível como um orientador do comportamento social e serve como forma de funcionamento e desenvolvimento para uma aceitação da vida em sociedade.

Uma exaltação do papel dos construtores alemães do conceito de negócio jurídico deve ser feita: é a contribuição mais importante ao Direito Privado nos últimos tempos, ou talvez a grande contribuição moderna ao Direito Privado. E e está assentado na ideia de vontade, dando ênfase a mais inesquecível caraterização da vida moderna: a de liberdade. E uma liberdade a respeito da qual podem advir efeitos que somente a liberdade reconhecida e aclamada poderiam evidenciar: a de permitir obrigar-se.

Não se pode olvidar que, à semelhança do negócio jurídico, a vontade contratual está determinar a pratica do ato e, tal o negócio jurídico, integrando parte a sua definição como um acordo de vontade apto a produzir efeitos jurídicos. Fenômeno novo elaborado pela magnificência alemã, que viu no negócio jurídico mais do que uma unidade conformadora, mas uma forma de aspiração a buscar a satisfação de seus interesses por um único ato de vontade, da parte contratante, em correspondência com outra declaração correspondente.

O indivíduo tem consciência na sociedade moderna de que por meio de prestações recíprocas ambas as partes dos contratos bilaterais encontrarão forma de conceber a justiça em um contrato, segundo cada regimes correspondentes em vigor. Certamente é uma justiça particulatizada, uma justiça liberal, em oposição a uma justiça igualitária, e geradora de desigualdade ou, no mínimo, de uma falta de uma paridade de situações. E além disso permite considerar uma justiça individual em contraste com uma justiça coletiva.

Essa concepção liberal de contrato, com os seus contornos de igualdade de posições em situações materialmente desiguais, segundo os ditames de uma ampla autonomia da vontade, do qual o Código Napoleão procurou preservar e garantir. Desse ponto de vista o contrato era a liberdade irrestrita de uma ou outra parte, a partir de um exercício descontrolado dessa liberdade, e dela brota espontânea e naturalmente um tipo malfeito de equilíbrio de prestações recíprocas de ambos os contratantes que se pauta, em consequência, por tipo de lei de oferta e procura segundo o qual, por exemplo, o interessado em vender ou dar em locação um determinado bem com um preço exagerado ou um empréstimo de dinheiro nas mesmas condições.

O velho modo de cumulação de riqueza e vantagens para uma parte mais forte dividiu muitos interesses e nem sempre em consonância com uma interação a considerar entre uma produção desenvolvida de uma dada economia e as necessidades da sociedade. Essas circunstâncias levaram a amenizar a autonomia da vontade e a provocar a intervenção do 
Estado. Aparecem, então, teorias sobre a intervenção do Estado nos contratos, em um dirigismo contratual, ao ponto de se falar em uma publicização dos contratos. E é com o desenvolvimento das sociedades que o velho modo de ver o contrato entra em linha de colisão com as transformações que os grupos sociais de cada país conhece, ou por meio de movimentos políticos ou, mais especialmente, movimentos sociais.

O surgimento de movimentos sociais constitui a segunda grande fonte material que, em união com o pensamento apurado da Civilística da época pode ter provocado uma verdadeira ruptura com o Século XIX. Falando com exatidão, a construção de conceitos jurídicos encontra certo paralelismo na formação do subproduto mais refinado do pensamento jurídico desde Roma, que foi o Pandectismo. O trânsito para o Século XX marca, em muitos aspectos, os pontos de confronto que as contradições e polarizações da época já acentuavam. O conceitos e valores sociais, aspectos da liberdade e de justiça social não passaram em branco aos pensadores de cada ocasião. Em uma espécie de construção ampla da evolução do pensamento social, que abrangeu desde românticos como San Simon e sistematizadores como Comte, assim como outros autores que conceberam verdadeiros postulados em um epistemologia social, no curso da evolução de um pensamento social, etapas intelectuais são vencidas e redundarão em um complexo que bem poderia ser resumidos com o nome de Filosofia Social.

Importa sublimar que se a concepção jurídica mais apurada pôde construir a figura da relação jurídica, do direito subjetivo e da pretensão, dentre outros, concebeu a mais importante construção teórica do Direito Privado: o negócio jurídico. A essência do negócio jurídico é a liberdade, tal como é captada pelo jurista. Por outro lado, a oposição que o pensamento do Século XIX reconhece não apenas como uma liberdade essencial, mas pela possibilidade de um agir em liberdade, sem a opressão do Estado ou de uma outra opressão estabelecida, vai redundar em um conjunto de reações forjadas entre variadas tendências de cunho social, socializante, socialista, comunista e até anarquista. Um novo e considerável passo para as diferenças socioeconômicas e de modos de vida é o que todos eles chamam a atenção. Entretanto, os movimentos sociais acentuam mais além: a elevação do nível cultural das massas populares, a formação de uma personalidade desenvolvida universalmente e o fim das diferenças de classe.

Nas suas críticas, os socialistas utópicos (assim, ironicamente, denominados pelos discípulos do socialismo científico) do gênero de Saint-Simon, Fournier e Owen, levantaram questões incômodas e buscaram uma conscientização das grandes massas operárias para resolver a questão entre a liberdade do homem, por um lado, e por outro, as necessidades de desenvolvimento social, que era uma necessidade histórica, de modo a evitar a arbitrariedade e o indeterminismo dos feitos humanos. A necessidade que o ser social desenvolveu historicamente exige a reorganização do trabalho e das condições de vida, com a necessária intervenção do Estado. Criados estavam os fatores para o surgimento do Manifesto de Karl Marx e Friedrich Engels. Esse novo pensamento prega uma nova concepção de mundo e alça a classe operaria a uma condição revolucionária, destinada a terminar com o domínio da 
burguesia, destruir o capitalismo e construir uma nova sociedade, que seria mais avançada e mais justa.

A significação mais evidente de esses acontecimentos, antes de tudo, é que permitem orientar uma interpretação das propostas de soluções dos problemas suscitados e da sua influência nos anos que se seguem, especialmente nos modos de produção e seus efeitos nos demais aspectos da vida social, incluindo o aspecto espiritual do processo histórico que tanto sensibilizou os pensadores da época. Tudo isso fez possível realizar, de maneira mais eficaz e proporcional, embora de maneira progressiva, as grandes ideias e pensamentos que forjaram os primeiros movimentos pró-consumidor nos países que estavam em curso do desenvolvimento industrial, como a França, a Alemanha, a Inglaterra e, principalmente, os Estados Unidos da América.

Uma das tarefas primordiais e urgentes que afrontava a jovem República norteamericana era luta pela melhoria das condições de trabalho locais e contra a exploração do trabalho feminino e infantil. Nas alturas dos anos 1800 as ideias estão longe de serem aceitas, mas, no que se refere aos EUA, Josephine Lowell criou a "New York Consumers League", uma associação de consumidores que tinha por objetivo essas mesmas lutas. Embora não fosse consumerista pura, por meio de listas, chamadas "listas brancas", divulgava-se o nome dos produtos que os consumidores deveriam escolher preferencialmente. Conquanto não desfrutasse de ampla aceitação, as empresas que produziam e comercializavam respeitavam os direitos dos trabalhadores, como, por exemplo, pelo pagamento de um salário mínimo, horários de trabalho razoáveis e condições de higiene condignas, tinham seu registro positivo de boas práticas. E assim foi iniciada a forma de influenciar a conduta das empresas tendo como forma de pressão, o poder de compra dos consumidores.

Em fins dos anos18, Florence Kelley deu prosseguimento a esse trabalho ao reunir a associações de Nova Iorque, Boston, Chicago, Filadélfia e criar a Liga Nacional dos Consumidores (National Consumers League), com ênfase inicial nas condições de mulheres e crianças nas fábricas de algodão. A NCL, entretanto, usava a força dos consumidores direcionada para uma causa social, exprimindo mais uma vez a ideia do que seria a defesa dos bons produtos ou a qualidade industrial.

É sabido que a matéria encontrava-se ao ponto de evolução quando no início do Século XX, os Códigos Civil da Alemanha e do Brasil entram em vigor, mas, também, vem a lume o romance A Selva (The jungle), de Upton Sinclair, de inspiração socialista, no qual descreve, de maneira bastante realista, as condições de fabricação dos embutidos de carne e o trabalho dos operários dos matadouros de Chicago, bem assim os perigos e as precárias condições de higiene que afetavam tanto os trabalhadores como o produto final. A inclusão da obra de Siclair na sucessão de acontecimentos teve tamanha repercussão que décadas de resistência foram vencidas, culminando com a sanção, pelo Presidente Roosevelt, da primeira lei de alimentação e medicamentos (a Pure Food and Drug Act - PFDA), em 1906, e da lei de inspeção da carne (a Met Inspection Act), em 1907. 
São esses os traços característicos da proteção do consumo no Século XIX. E primeiro lugar: um período dedicado às condições do trabalho. Em segundo lugar: é um período de transição, dos movimentos sociais trabalhistas para o que seria uma verdadeira bifurcação com os movimentos em prol dos consumidores.

Todos esses movimentos, principalmente o dos trabalhadores, tiveram grande aceitação entre as multidões e não são mais do que um derradeiro reflexo do pensamento do Século XIX. Há todavia, um traço de diferença com o Direito Civil: é resultante de movimentos capilarizados por meio de greves, protestos e grandes manifestações de repercussão geral.

O conceptualismo do Direito privado forjou o negócio jurídico a partir da evolução do pensamento e das condições do uso. O desenvolvimento das lutas sociais que conduziram as leis trabalhistas e de amparo ao trabalhador debilitado deram forma a uma ampliação de um pensamento social que, entre o espiritual e o material, levou, aceitação do mundo a um campo do idealismo dos problemas sociais com tudo aquilo que lhe dizia respeito`: da origem do conhecimento, da verdade e da autenticidade de critérios e a maneira de tratar cada solução dada aos problemas.

Se da aceitação do primado dos conflitos sociais dependia a resposta à questão da existência e do caráter das leis inerentes à interconexão dos problemas do mundo, deu-se uma resposta que muito resultou das conclusões dadas pelo Direito Civil: a relação do direito com a realidade social, a compreensão dos acontecimentos históricos e os princípios sobre as calamidades sociais, tão terrivelmente sofridas pelos trabalhadores nas sociedades com o antagonismo de classe (opressão por miséria ou alguma outra vulnerabilidade) deve encontrar nas relações com o Direito Civil a estrutura para estabelecer o padrão de conhecimento e adaptálos da melhor maneira, mesmo diante de possíveis erros e defeitos e uma tal concepção que pude tornar possível os mesmos padrões já usados no Direto Comercial.

A forma histórica elaborada pelo Direito Civil percorreu longo caminho para forjar o Direito Comercial, embora tenha conhecido muitas variantes. Era a maneira espontânea e ingênua que se manifestou nas relações comerciais, com o uso das figuras do contrato e das obrigações, seguindo a forma superior já elaborada e reconhecida do Direito Civil. As variantes é de mencionar são antes de mais nada de cunho formal que de um tipo ideal objetivo para o qual o espírito da lei é exterior e independente da consciência dos indivíduos, independente da matéria, da natureza, ou anterior a ela, como razão universal, vontade universal inconsciente que determinaria todas as foras do Direito Comercial.

Em contraste com a prematura legislação trabalhista, aquela relacionada aos consumidores somente nos anos 1960, pelas mãos do Presidente John Fitzgerald Kennedy, encaminhou Mensagem Especial ao Congresso dos Estados Unidos da America sonte Proteção dos interesses do Consumidor Na década seguinte, dos anos 1970, a Organização das Nações Unidas, pela sua Comissão de Direitos Humanos reconheceria os direitos básicos dos consumidores, e na década seguinte, a de 1980, o Conselho Social e Econômico da Assembleia 
Geral das Organização das Nações Unidas deliberou a Resolução 39-248 com uma série de normas internacionais para proteção do consumidor.

Um destaque extraordinário deve ser feito entre as primeiras leis de proteção ao consumidor, no qual destacamos as leis francesas da década de 1970 que permitia o período de sete dias para refletir sobre a compra, publicidade enganosa, e que protegiam o consumidor contra os perigos do crédito e das cláusulas abusivas.

O progresso técnico levou ao amadurecimento no Brasil, que começou a discutir ainda de maneira acanhada as primeiras associações civis e entidades governamentais voltadas para esse fim. E já na década de 1970 foi criado no Rio de Janeiro o Conselho de Defesa do Consumidor (Condecon), em 1974. Em Curitiba, a Associação de Defesa e Orientação do Consumidor (ADOC), em 1976. Também em 1976, em Porto Alegre, a Associação de Proteção ao Consumidor (APC). Em maio de 1976, pelo Decreto nº 7.890, o Governo de São Paulo criou o Sistema Estadual de Proteção ao Consumidor, que previa em sua estrutura, como órgãos centrais, o Conselho Estadual de Proteção ao Consumidor e o Grupo Executivo de Proteção ao Consumidor, depois denominado Procon.

No decurso dos acontecimentos, a edição do Plano Cruzado, provocou a primeira grande mudança, ao despertar o sentimento de direitos, na segunda metade da Década de 1980. Mas o ponto culminante foi a Constituição de 1988 ao estabelecer como dever do Estado promover a defesa do consumidor e assinar prazo para a elaboração de um código para esse fim.

O aparecimento do Código de Defesa do Consumidor trouxe consigo uma experiência já conhecida na legislação do trabalho, a Consolidação das Leis do Trabalho e, também o que já era consagrado há muito no Direito Comercial (o Código Comercial era do Século XIX), a busca de uma coerência na compreensão da linguagem e na estrutura lógica do diploma legislativo. Uma terminologia estranha e não habitual ao exprimir a vontade do legislador evitaria interpretações equivocadas e eventualmente postas no ridículo.

Se se pensar que a legislação trabalhista (CLT) a comercial (o Código Comercial) tinham o contrato e as obrigações como figuras-chave, a utilização apriorística também no Código de Defesa do Consumidor proporcionaria, além da virtude do impacto, as virtudes de uma linguagem relativamente simples e sem abuso dos neologismos que tanto dificultam a leitura de alguns textos de lei e albergam o rico tesouro de palavras que a língua portuguesa oferece. Distinguiu-se o Código por não suprimir termos conhecidos como ocorreu no Direito Civil ao não usar o tão corriqueiro "desquite" na lei do divórcio e preferir "separação" e a popular, embora abominado pelos magistrados, a de "juiz peitado", pelo Código de Processo Civil de 1973.

A unidade do Código de Defesa do Consumidor não esconde a diversidade das fontes materiais na elaboração do novel diploma. A ação técnica de tutela dos direitos dos consumidores que o Código encerra esbarra com a possível caracterização de uma análise 
comum ao Direito Civil. Examinando o sentido e o valor dos dispositivos objeções poderiam ser erguidas para um tratamento comum na leitura do Código de Defesa do Consumidor no confronto com o Direito Civil. Torna-se patente que toda unidade de leitora não pode fechar-se em si mesma de modo a seguir orientações que pela unidade da disciplina não se manteria de pé somente por si.

São exemplos no Direito do Trabalho, a mais notável caracterização que sublinha a enorme importância desse ramo do direito é caracteriza pelo contrato de trabalho como um fato que determina sua realidade, qual seja a Teoria do contrato-realidade. De maneira que, presentes seus requisitos está configurado. Numa situação de utilização do Direito Civil, não prescindiríamos do consentimento mesmo tácito para configurarmos um contrato pelo Direito Civil. No Direito Comercial, a construção de um contrato como destinado a proporcionar lucro.

A fim de fazermos justiça às concepções que levaram à formação do Código de Defesa do Consumidor, um paralelo radical com o Direito Civil não seria possível. E não queremos deixar dúvidas de que devemos nos congratularmos com um retorno às formas matérias que serviram de fonte que decidiram a sorte do consumidor sem o qual o arrastaria consigo no malogro de buscar a tutela do interesse no consumo.

Ao dizer a verdade sobre o Direito do Consumidor, tal como ocorreu e foi confirmado pelos estudiosos do Direito do Trabalho e do Direito Comercial, haveríamos de nos lançar de braços para as fontes que conduziram à elaboração do Direito do consumidor e evitar que se corresse nos riscos próprios de uma existência. Entre o Direito Civil e o Direito do Consumidor pode-se mesmo travar uma verdadeira luta por um saber objetivo por respeito a um e a outro como verdade possível, embora possam não se entender.

O que na linguagem do Direito Civil se entende por consenso e forma que o acompanha para forma dos contratos do Direito do Consumidor pode, além de ser uma necessidade formal, ser uma maneira de dar uma forma regimis comum. A existência do contrato no Direito do Consumidor, entretanto, não obedece ao formalismo da posição do consentimento. O estado do contrato nas relações de consumo não toma como essencial o consenso da celebração do contrato, mas, em verdade, outra é maneira de determinar o característico que acompanha o contrato na relação de consumo: a situação do consumidor.

Para encontrar um objeto próprio do seus sistema contratual, devemos avançar para o objetivo do próprio Direito do consumidor. Interessa-lhe não o formalismo do contrato, mas a prestação correspectiva. Quer isso dizer que o direito do consumidor não deve se ocupar da forma civil do contrato no texto do Código do Consumidor para criar um tipo de ajuste ou conformação nos seus dispositivos, mas uma realidade própria: a das relações jurídicas em confronto. Se ao Direito Civil o consenso seria a maneira de chegarmos a realidade do contrato, não se poderia compreender como o Direito do Consumidor se voltaria para essa mesma maneira de tutela. Essa breve excursão quer mostrar a única tutela possível é a original e genuína, na qual se usa a fórmula de troca com quem se encontra como consumidor. A base econômica de contraprestação acompanhada da figura do consumidor é a relação recíproca que 
ocorre nos contratos de consumo, possivelmente por uma inspiração dos países anglo saxônicos cuja base não é o formalismo que marca o regime contratual do consenso como ocorre em nosso País.

Em prosseguimento, ao reconhecermos o progresso dos negócios na figura central e basilar dos contratos no Direito do Consumidor. Vimos que a noção moderna de contrato se origina no labor dos juristas do Direito Intermédio Continental, fundada em alguns vislumbres dos jurisconsultos do Direito Justinianeu e na ideia tipicamente romana de que a vontade pode, por si só, criar obrigações.

A determinação de um conceito abstrato e geral do contrato é o resultado de dois movimentos: o dos juristas, conduzidos consciente ou conscientemente a força a letra e o espírito da lei romana para adapta-la às necessidades da época: e dos canonistas que partindo da ideia de supremacia da Igreja sobre Roma, lutaram por novas concepções jurídicas. Eles abriram o caminho à formulação moderna do conceito de contrato.

Ao se examinar essa questão do contrato, convém acentuar que, nos compromissos do fornecedor para com o consumidor, toda a concepção do contrato em suas características mais conhecidas deve ser observadas. Mas, na esfera específica que o Direito do Consumidor apresenta, não seria uma contradição a premissa de um regime contratual paritário ou igualitário? Alicerçados no regime contratual específico dos contratos, haveria de se dizer serem iguais a posições de fornecedor e consumidor? A melhor decisão que se poderia apresentar seria aquela na qual havia uma contraprestação que se espera ver cumprida.

A essência do contrato nas relações de consumo está na complexidade e na contraposição do consumidor com o fornecedor. E essa formulação resulta da premissa de que a tarefa do contrato não é dar consequência ao consenso que obriga como ocorre no Direito Civil, mas no desequilíbrio de situações das relações contrapostas entre quem negocia com um consumidor e o próprio consumidor.

Essa forma de pensar proposta conclui um esclarecimento que põe em primeiro plano o caráter específico do contrato nas relações de consumo como assentado na justeza do cumprimento da obrigação esperada pelo consumidor e não no cumprimento do consenso formador do contrato como, por sua vez, se pauta o contrato no Direito Civil.

O contrato nas relações de consumo haveria de se definir como realizador de atos eficazes de oferta e aceitação do consumidor no qual a operação realizada é a de satisfação do consumidor. Se o termo contrato denota um compromisso formal que consolida um consenso a seguir obrigatoriamente seguido, o caráter consumerista cria no negócio o predomínio da relação de contraposição realizada como uma própria condição para o contrato ser assim entendido. 
O contrato do Direito Civil como fonte de obrigação assume um papel diverso daquele do Direito do Consumidor. No Direito Civil a obrigação surge do contrato; no Direito do Consumidor a obrigação é uma promessa que os contratantes fazem para que, no confronto entre um e outro, encontre o segundo, mais vulnerável a satisfação da promessa esperada e darse assim como formado e concluído o contrato. Em uma perspectiva de parte correspondente, a obrigação do cocontratante civil que não venha a ser cumprida é causa de inadimplemento. No Direito do Consumidor, a obrigação é uma promessa na qual sua frustação macula a própria contratação supostamente obrigada pelo consenso.

A nosso ver, a obrigatoriedade Civilística na qual se basearia o Direito Civil não é paralela ao regime da contratação consumerista. Tampouco defendemos aqui a ideia norteamericana na qual o contrato é uma promessa de troca. A proposta em um contrato integrará no regime de consenso o contrato de Direito Civil. Nas relações de consumo a proposta sofre um diformismo juridico que não retira do contrato sua condição, mas introduz uma forma diferente de atuação: a de que a proposta só será eficaz se condicionada à própria realização do contrato.

A falta de unidade nos regimes contratuais manifesta-se não somente na maneira como o contrato é executado, mas também nos fundamentos da ideia de obrigatoriedade dos contratos. Mas seria erro perigoso querer conceber a existência de uma figura sem um parâmetro do tipo contratual. Na realidade, assim como o Direito Civil não sabe até hoje porque um contrato obriga - a despeito das várias teorias propostas -, uma nova fonte de dúvidas levaria ao agravamento de questões sobre o Direito do Consumidor para essa dúvida sobre o fundamento da obrigatoriedade dos contratos de consumo.

Além do elemento formador do Direito do Consumidor, encontramos nas chamadas fontes materiais do Direito do Consumidor o elemento técnico que o definirá como um novo ramo do Direito. Sob esse aspecto, podemos assinalar algumas ideias e resultados de grande valor como um tipo de conclusão para estas linhas. É inegável que a dogmática contratual do Direito Civil e seus estudiosos enriqueceram o regime contratual do consumidor com toda uma série de excelentes análises teóricas e práticas, que exploraram até pela primeira vez domínios novos, nas desequilibradas relações entre produtor, fornecedor e consumidor, afastando-se daquelas puramente iguais entre os agentes do negócio jurídico, ou mais propriamente as partes nos contratos disciplinados pelo Direito Civil. Surgiu nesse ponto uma nova problemática que significa uma ampliação essencial da forma do Direito Civil aproveitada nos contratos disciplinados pelo Direito do Consumidor. São fundamentais as formas do Direito Civil nos contratos e nas relações de consumo, pois se um lado oferecem as relações contratuais do Direito Civil a possibilidade de empréstimos das suas características fundamentais, restará ao Direito do Consumidor manter a características peculiares que o determina. Por fim, deve-se notar especialmente que, a compreensão por parte do jurista, de que essa forma civil usada no Direito do Consumidor muitas vezes também absorve mais do que uma formalização do Direito, e que nalguns casos até ao ponto de anular as regra do Direito do Consumidor. A forma que o Direito do Consumidor usa foi desenvolvida e coroada pelo Direito Civil e segue por uma espécie de estética civilística (como maneira talvez de se denominar esse empréstimo de 
forma). Deve-se notar em um caráter especial que a compreensão por parte desses contratos e dos diversos problemas de natureza estão a exigir, muito ultrapassam os temas e os problemas que o Século XIX produziu a esse respeito. Nunca se insistirá demasiado neste ponto: o direito do consumidor não é só um apelo profético ao Direito Civil para conformar as novas fontes materiais do Direito, senão também uma nova técnica e sob os muitos aspectos tão valiosa que poderá ser aproveitada em outros ramos do Direito. Esses mesmos problemas que suscitam as soluções propostas tendem a ser tratados de maneira muito mais séria e penetrante quando levados a solucionar também as questões do Direito Civil, e o resultado possa talvez ser uma nova ruptura: a do Século XX.

\section{REFERÊNCIAS}

ALVES, José Carlos Moreira. Direito romano. $5^{\text {a }}$ ed. Rio de Janeiro: Forense, 1983.

BEVILÁQUA, Clóvis. Teoria Geral do Direito Civil. 2a ed. Rio de Janeiro: Rio, 1980.

BOLSON, Simone Hegele. Direito do consumidor e dano moral. Rio de Janeiro: Forense 2002.

CARIOTA FERRARA, Luigi. Il negozio giuridico nel diritto provato italiano. Nápoles: Morano,

CAVALIERI FILHO, Sergio. Programa de Direito do Consumidor. São Paulo: Atlas, 2008.

CHAMOUN, Ebert. Instituições de Direito Romano. $6^{\text {a }}$ ed. Rio de Janeiro: Rio, 1977.

DESSAUNE, Marcos. Desvio Produtivo do consumidor. $2^{\mathrm{a}}$ ed.Vitória: Edição do Autor, 2017.

ENNECCERUS, Ludwig; KIPP, Theodor; WOLFF, Martín. Tratado de derecho civil. V. I, trad. Blas Pérez González e José Alguer.Barcelona: Bosch, 1934.

ESPÍNOLA. Eduardo. Sistema do Direito Civil. Rio de Janeiro: Rio, 1977.

FEHR, Hans. Deutsche Rechtsgeschichte. Berlim: Walter de Gruyter \& Co. 1952.

FERNANDEZ BULTE, Julio. Historia del estado y de derecho em la antigüedad. Havana: Instituto Cubano del Libro, 1971.

FLUME, WERNER. El negocio jurídico. Trad. José María Miquel gonzález e Esther Gómez Calle. Madri: Fundación Cultural del Notaiado, 1992.

HUBER, Eugen. El derecho y su realización, problemas de legislación y de filosofia del derecho. Trad. Hertha Grimm. Madri: Reus,1929.

KAHN-FREND, Otto. Il lavoro e la legge. Trad. Guido Zangari, Milão; Giuffrè, 1974.

LARENZ, Karl. Derecho Civil. Trad. Miguel Izquierdo y Macías-Picavea. Madri: Revista de Derecho Privado, 1978. 
LE ROY, Yves; SCHOENENBERGER, Marie-Bernadette. Introduction Générale au droit suisse. Genebra: Schulthess Médias Juridiques, 2002.

MACEDO, Sívio de. Curso de filosofia social. $2^{\text {a }}$ ed. Rio de Janeiro: Freitas Bastos, 1997.

MARQUES, J. Dias. Noções elementares de direito civil. Lisboa: 1973.

MITTEIS, Heinrich. Deutsche Privatrecht. Munique: C. H. Becksche, 1959.

MITTEIS, Heinrich.Deutsche Rechtsgeschichte. Munique: C.H. Becksche, 1988.

PERRET, Louis. Derecho del consumo y protección al consumidor. Santiago do Chile: Universidad de los Andes, 1999.

PLANITZ, Hans. Deutsche Rechtsgeschichte. Viena: Hermann Böhlaus Nachfolger, 1950.

PLANITZ, Hans. Principios de derecho privado germânico. Trad. Carlos Melon Infante. Barcelona: Bosch, 1957.

PEIXOTO, José Carlos Marques. Curso de direito romano. $4^{\mathrm{a}}$ ed. Rio de Janeiro: Renovar, 1997.

PEREIRA, Caio Mário da Silva. Instituições de direito civil. $19^{\mathrm{a}}$ ed. Rio de Janeiro: Forense, 2001.

RÁO, Vicente. Ato jurídico. $3^{\mathrm{a}}$ ed. São Paulo: Saraiva, 1961.

RIBAS, Conselheiro Joaquim. Direito Civil Brasileiro. 2a ed. Rio de Janeiro: Rio, 1977.

SERPA LOPES, Miguel Maria de. Curso de direito civil. $8^{\mathrm{a}}$ ed. Rio de Janeiro: Freitas Bastos, 1996.

SERRANO, Pablo Jiménez. Introdução ao direito do consumidor. Barueri: Manole, 2003.

TAVARES, José. Os princípios fundamentais do direito civil. V. 1. Coimbra: Coimbra, 1922.

VOLTERRA, Eduardo. Instituciones de derecho privado romano. Trad. Jesús Daza Martínez. Madri: Civitas, 1988.

WEBER. Adolph Dietrich. Systematische Entwicklung der Lehre von den natürlichen Verbindlichkeiten und derem gerichtlicher Wirkung. 3 Bände. Schwerin: Bödner, 1784-1787. 